\title{
Changes in bone mineral density and bone metabolic indexes in ankylosing spondylitis mouse model complicated with osteoporosis
}

\author{
ZI-BING HU ${ }^{1,2}$, BO WEI ${ }^{2}$, SHAO-KE WU ${ }^{2}$, JIE-CONG SUN ${ }^{2}$, MIN XIANG $^{2}$ and ZHONG-MIN ZHANG ${ }^{1}$ \\ ${ }^{1}$ Orthopaedic Center, The Third Affiliated Hospital of Southern Medical University, \\ Guangzhou, Guangdong 510000; ${ }^{2}$ Orthopaedic Center, The Affiliated Hospital of \\ Guangdong Medical University, Zhanjiang, Guangdong 524000, P.R. China
}

Received November 22, 2017; Accepted May 14, 2018

DOI: $10.3892 /$ etm.2018.6220

\begin{abstract}
Changes in bone mineral density and bone metabolic indexes in a model of ankylosing spondylitis (AS) mice complicated with osteoporosis (OP) were investigated. $\mathrm{BLAB} / \mathrm{c}$ mice were used as the subjects. AS was induced using proteoglycan, and OP was induced using tail suspension method. The mice were randomly divided into four groups: AS group, OP group, AS + OP group and negative control group. Changes in bone mineral density, bone strength, serum calcium $(\mathrm{Ca})$, phosphorus, alkaline phosphatase (ALP) and tartrate-resistant acid phosphatase (TRACP), in mice of each group were detected and compared. There were statistically significant differences in bone mineral density and bone strength among groups. Compared with the negative control group, bone mineral density and bone strength in the AS, the $\mathrm{OP}$ and the AS + OP groups were significantly decreased, and the lowest bone mineral density and bone strength were found in the $\mathrm{AS}+\mathrm{OP}$ group $(\mathrm{P}<0.05)$. There were no significant differences in bone mineral density and bone strength between the AS group and the OP group. Significant differences in serum Ca, ALP and TRACP but not in serum phosphorus were found among groups. Compared with the control group, serum levels of $\mathrm{Ca}$ and TRACP in the AS, the OP and the AS + OP groups were significantly increased, while levels of ALP were obviously decreased $(\mathrm{P}<0.05)$. Bone destruction in AS mice complicated with osteoarthritis was more serious than that in mice with simple AS.
\end{abstract}

Correspondence to: Dr Zhong-Min Zhang, Orthopaedic Center, The Third Affiliated Hospital of Southern Medical University, Guangzhou, Guangdong 510000, P.R. China

E-mail:nfyzzm@126.com

Key words: ankylosing spondylitis, osteoporosis, bone mineral density, bone metabolism

\section{Introduction}

Ankylosing spondylitis (AS) is a type of chronic rheumatic disease with chronic inflammation of axial joint as the main type, and characterized by sacroiliitis and spondylitis, which mainly involves the sacroiliac joint, spinal apophysis, paravertebral soft tissues and peripheral joints. AS is usually accompanied with extra-articular manifestations (1). The prevalence rate of AS is different in different region, and prevalence rate of this disease is approximately $0.3 \%$ in China. Males were more prone to be affected with AS and male/female ratio is approximately 2-3:1, AS mainly affects people aged 13-31 years, and the highest incidence was observed in people aged 20-30 years, while occurrence of AS in people aged above 40 years and below 8 years is rare. With the progress of science and technology and deepening of research, considerable progresses have been made in the diagnosis and treatment of AS. It has been proved that the human leucocyte antigen (HLA)-B27 is closely related with the occurrence of AS (2), but the exact pathogenesis of AS remains unknown.

Inflammation and hyperostosis are the main pathological changes in AS. Pathological new bone formation can cause osteophyte, resulting in spinal and sacroiliac joint ankylosis. In addition to inflammation and hyperostosis, osteoporosis (OP) is also a widely-recognized complication in AS patients. In the early stages of disease, lesions in bone trabeculae may increase the risk of vertebral fractures and cause severe nerve injury (3). There are approximately $19-62 \%$ of AS patients who suffer from OP, and $9-42 \%$ of AS patients are complicated with vertebral fractures $(4,5)$. Hyperostosis and OP, as two opposite processes, bring great challenges to the clinical diagnosis and treatment of AS. The prevention and treatment of hyperostosis may aggravate $\mathrm{OP}$, and vice versa.

In this study, BLAB/c mice were used as subjects. AS was induced using proteoglycan, and OP was induced using the tail suspension method. Moreover, the model of AS mouse complicated with OP was established to study and compare the changes in bone mineral density and bone metabolic indexes, so as to provide references for clinical diagnosis and treatment of AS. 


\section{Materials and methods}

Animals. Forty BLAB/c healthy female mice in clean grade aged 8 weeks, weighing $20.5 \pm 2 \mathrm{~g}$, were provided by Laboratory Animal Center of Guangdong Medical University. Mice were randomly divided into four groups with 10 mice in each group. Mice were fed in separate cages at room temperature $22 \pm 1^{\circ} \mathrm{C}$ under the relative humidity of $60-70 \%$ with free access to water and food. All animal experiments were approved by the Animal Ethics Committee of Affiliated Hospital of Guangdong Medical University (Zhanjiang, China).

Materials and reagents. Proteoglycan (Pierce; Thermo Fisher Scientific, Inc., Waltham, MA, USA); Freund's complete adjuvant (Sigma; Merck KGaA, Darmstadt, Germany); Freund's incomplete adjuvant (Sigma; Merck KGaA); calcium (Ca) assay kit (standard colorimetric method), phosphorus assay kit (standard colorimetric method), alkaline phosphatase (ALP) assay kit and tartrate-resistant acid phosphatase (TRACP) kit were purchased from Nanjing Jiancheng Bioengineering Institute (Nanjing, China); 721 spectrophotometer (Shanghai Precision and Scientific Instrument Co., Ltd, Shanghai, China); electronic analytical balance (Shanghai Precision and Scientific Instrument Co., Ltd.); small animal dual-energy X-ray bone densitometer (AA400, Kodak, Rochester, NY, USA); AG-1S universal material tester (Ag-1S, Panasonic, Tokyo, Japan).

Establishment of AS mouse model (AS group). AS mouse model was established according to the standard method of proteoglycan induced AS (6-8). Multiple joint synovitis including spondylitis, ankylosis and malformation proved that the model was successfully established. Ten susceptible $\mathrm{BLAB} / \mathrm{c}$ mice were adaptively fed for 1 week and then AS was induced using proteoglycan. Each mouse was injected intraperitoneally with $0.15 \mathrm{ml}$ proteoglycan emulsion $(100 \mu \mathrm{g}$ proteoglycan + Freund's complete adjuvant), followed by another intraperitoneal injection of $0.15 \mathrm{ml}$ proteoglycan emulsion $(100 \mu \mathrm{g}$ proteoglycan + Freund's incomplete adjuvant) at the 3rd and 6th week.

Establishment of OP mouse model (OP group). After adaptive feeding for 5 weeks, OP mouse model was established using tail suspension method. Mice were suspended via tail-suspension rotating device to hang the posterior limbs. Posterior limbs were kept in an artificial weightless state. Mice were allowed to move freely in vertical direction without damaging the tail. Mice were observed every day and the suspension position was adjusted according to the situation. Mice were suspended for 5 weeks.

Establishment of model of AS mice complicated with $O P$ $(A S+O P$ group $)$. Mouse model of AS complicated with OP was established using proteoglycan combined with tail suspension method. After adaptive feeding for 1 week, each mice were injected intraperitoneally with $0.15 \mathrm{ml}$ proteoglycan emulsion (100 $\mu \mathrm{g}$ proteoglycan + Freund's complete adjuvant), followed by intraperitoneal injection of $0.15 \mathrm{ml}$ proteoglycan emulsion $(100 \mu \mathrm{g}$ proteoglycan + Freund's incomplete adjuvant) at the 3rd and 6th week. Mice were suspended via tail using the tail-suspension rotating device 5 weeks after the beginning in the same way as described in Establishment of OP mouse model (OP group)'. Modeling was sustained for 10 weeks.

Determination of bone mineral density of mice. Mice were sacrificed by via cervical dislocation. One femur, tibia and lumbar vertebrae bone were collected and the soft tissues attached to the bone tissues were removed. Femur and lumbar vertebrae bone were wrapped with the gauze impregnated with normal saline, and stored at $-20^{\circ} \mathrm{C}$. Tibia was fixed with formaldehyde solution for the detection of morphometric indexes. Bone mineral density was measured using the dual-energy X-ray bone densitometer (Kodak, Rochester, NY, USA).

Bone biomechanical determination. The 3-point bending test was performed on tibia of mice, and the tibia was pressed using the AG-1S universal material machine (load measurement accuracy $=0.01 \mathrm{~N}$, speed $=1.5 \mathrm{~mm} / \mathrm{min}$, and span $=8 \mathrm{~mm}$ ) until tibia rupture. Then the internal and external diameters and cortical bone thickness on the fractured end were measured. The load-deformation curve was plotted according to the results, the maximum load was recorded, and the bending elastic modulus was calculated (9).

Determination of bone metabolic indexes. The eyeballs were removed from mice to collect blood, and the blood was centrifuged at 2,500 $\mathrm{x}$ g to collect serum. Then the serum Ca, ALP and TRACP were detected according to the instructions.

Statistical analysis. Statistical Product and Service Solutions (SPSS) 17.0 software (SPSS Inc., Chicago, IL, USA) was used for the statistical analysis of all data. Data were presented as mean \pm standard deviation. Analysis of variance followed by post hoc test (Least Significant Difference) was used for comparisons among multiple groups. $\mathrm{P}<0.05$ was considered to indicate a statistically significant difference.

\section{Results}

General conditions of mice. Mice were observed and the situations were recorded every day. All mice were in good condition during the experiment and there was no obvious infection or accidental death. Toe swelling began to occur in limbs of AS mouse model at 3 weeks after injection of proteoglycan, and symptoms were aggravated with the prolonged treatment. Multi-joint synovitis, including spondylitis, occurred, resulting in dynamic joint ankylosis and deformity, which prove that the model was successfully established. The weight of mice in each group before the experiment was compared by using the variance analysis. Weight of mice in each group showed no significant difference to the pretreatment level $(\mathrm{F}=0.95$, $\mathrm{P}=0.88$ ). With the increase of time, the body weight of each group increased obviously compared with that before the experiment. t-test was used to compare the body weight of each group before experiment and before death. There was significant difference in body weight between each group before experiment and before sacrifice. The comparison between the control group and the OP group before the test and before the death was $7.09(\mathrm{P}<0.01), 6.73(\mathrm{P}<0.01)$, $6.85(\mathrm{P}<0.01), 4.87(\mathrm{P}<0.01)$ respectively. Compared with the 
Table I. Changes in body weight of mice in each group before and after experiment.

\begin{tabular}{lcc}
\hline & \multicolumn{2}{c}{ Weight $(\mathrm{g})$} \\
\cline { 2 - 3 } Groups & Before experiment & Before sacrifice \\
\hline Control & $21.55 \pm 2.08$ & $28.87 \pm 1.98^{\mathrm{a}}$ \\
AS & $21.71 \pm 1.99$ & $27.23 \pm 2.08^{\mathrm{a}, \mathrm{b}}$ \\
OP & $21.64 \pm 2.01$ & $28.06 \pm 1.89^{\mathrm{a}}$ \\
AS + OP & $21.52 \pm 2.04$ & $25.45 \pm 2.01^{\mathrm{b}}$
\end{tabular}

${ }^{\mathrm{a}} \mathrm{P}<0.05$, compared with those before the experiment; ${ }^{\mathrm{b}} \mathrm{P}<0.05$, compared with the control group. AS, ankylosing spondylitis; OP, osteoporosis.

Table II. Comparison of bone mineral densities of mice in each group.

\begin{tabular}{lcc}
\hline & \multicolumn{2}{c}{ Bone mineral density $\left(\mathrm{g} / \mathrm{cm}^{3}\right)$} \\
\cline { 2 - 3 } Groups & Femoral metaphysis & Lumbar vertebrae bone \\
\hline Control & $2.15 \pm 0.27$ & $2.42 \pm 0.21$ \\
AS & $1.53 \pm 0.21^{\mathrm{a}}$ & $1.62 \pm 0.16^{\mathrm{a}}$ \\
OP & $1.29 \pm 0.19^{\mathrm{b}}$ & $1.43 \pm 0.14^{\mathrm{b}}$ \\
AS + OP & $1.06 \pm 0.15^{\mathrm{b}}$ & $1.13 \pm 0.18^{\mathrm{b}}$ \\
\hline
\end{tabular}

${ }^{\mathrm{a}} \mathrm{P}<0.05$, ${ }^{\mathrm{P}}<0.01$, compared with the control group. AS, ankylosing spondylitis; OP, osteoporosis.

control group, the weight of mice in the OP group was not changed significantly, while weight in the AS and the AS + OP groups reduced significantly, and weight loss in the AS + OP group was the most significant among three treatment groups $(\mathrm{F}=3.46, \mathrm{P}=0.0025)$ (Table I).

Comparison of bone mineral densities of mice in each group. Bone mineral densities of femur and lumbar vertebrae bone isolated from mice were measured using dual-energy X-ray bone densitometer. Comparison of bone mineral density among groups was performed via analysis of variance $(\mathrm{F}=8.23$, $\mathrm{P}<0.001)$, and significant differences were found. Bone density of femoral metaphysis and lumbar vertebrae in the OP group was significantly decreased compared with that in the control group $(\mathrm{P}<0.001)$, suggesting that the OP model was established successfully. Bone mineral density in the AS group were lower than that in the control group $(\mathrm{P}=0.02)$, indicating that OP also exists in AS, but it was mild in the OP group. The bone mineral density in the AS + OP group was the lowest $(\mathrm{P}<0.01)$ (Table II).

Changes in bone biological activity of mice in each group. Biological activity of tibia in each group was detected using the 3-point bending method, and the maximum load and bending elastic modulus were calculated and compared. Significant differences in maximum load and bending elastic
Table III. Comparison of bone biological activity of mice in each group.

\begin{tabular}{lcc}
\hline Groups & Maximum load (N) & $\begin{array}{l}\text { Bending elastic } \\
\text { modulus (Gpa) }\end{array}$ \\
\hline Control & $15.46 \pm 0.56$ & $1.83 \pm 0.14$ \\
AS & $13.45 \pm 0.67^{\mathrm{a}}$ & $1.56 \pm 0.17^{\mathrm{a}}$ \\
OP & $11.02 \pm 0.74^{\mathrm{a}}$ & $1.24 \pm 0.15^{\mathrm{a}}$ \\
AS + OP & $9.45 \pm 0.87^{\mathrm{b}}$ & $1.05 \pm 0.19^{\mathrm{b}}$ \\
\hline
\end{tabular}

${ }^{\mathrm{a}} \mathrm{P}<0.05,{ }^{\mathrm{b}} \mathrm{P}<0.01$, compared with the control group. AS, ankylosing spondylitis; OP, osteoporosis.

Table IV. Comparison of bone metabolic indexes of mice in each group.

\begin{tabular}{lllll}
\hline Groups & Ca (mmol/l) & Pi (mmol/l) & ALP (U/l) & TRACP (U/l) \\
\hline Control & $2.25 \pm 0.31$ & $2.70 \pm 0.49$ & $156.90 \pm 16.96$ & $15.23 \pm 2.40$ \\
AS & $2.48 \pm 0.25^{\mathrm{a}}$ & $2.71 \pm 0.38^{\mathrm{a}}$ & $134.34 \pm 18.73^{\mathrm{a}}$ & $19.34 \pm 3.02^{\mathrm{a}}$ \\
OP & $2.69 \pm 0.28^{\mathrm{a}}$ & $2.65 \pm 0.46^{\mathrm{a}}$ & $120.38 \pm 20.76^{\mathrm{a}}$ & $20.34 \pm 2.99^{\mathrm{a}}$ \\
AS + OP & $2.83 \pm 0.23^{\mathrm{b}}$ & $2.65 \pm 0.37^{\mathrm{b}}$ & $96.78 \pm 17.28^{\mathrm{b}}$ & $25.26 \pm 2.57^{\mathrm{b}}$
\end{tabular}

${ }^{\mathrm{a}} \mathrm{P}<0.05,{ }^{\mathrm{b}} \mathrm{P}<0.01$, compared with the control group. Ca, calcium; ALP, alkaline phosphatase; TRACP, tartrate-resistant acid phosphatase; AS, ankylosing spondylitis; OP, osteoporosis.

modulus were found among groups $(\mathrm{F}=4.90, \mathrm{P}=0.006 ; \mathrm{F}=5.31$, $\mathrm{P}=0.002$ ). The maximum load and bending elastic modulus in the AS, the OP and the AS + OP groups were lower than those in the control group $(\mathrm{P}<0.05)$, and the lowest values were observed in the AS + OP group $(\mathrm{P}<0.01)$ (Table III).

Comparison of bone metabolic indexes of mice in each group. Metabolic indexes in serum of mice in each group were detected. No significant differences in serum Pi were found among groups $(\mathrm{F}=2.15, \mathrm{P}=0.12)$, but significant differences in contents of serum $\mathrm{Ca}(\mathrm{F}=8.86, \mathrm{P}<0.001)$, TRACP $(\mathrm{F}=10.53$, $\mathrm{P}<0.001)$ and ALP $(\mathrm{F}=9.21, \mathrm{P}<0.001)$ were observed among groups. Content of serum $\mathrm{Ca}$ in each experimental group was significantly increased compared with that in the control group, and the highest level was observed in the AS + OP group $(\mathrm{P}<0.01)$. Content of TRACP in each experimental group was also obviously increased compared with that in the control group, and the highest level was also observed in the AS + OP group $(\mathrm{P}<0.01)$. Contents of ALP in the AS, the OP and the $\mathrm{AS}+\mathrm{OP}$ groups were significantly decreased compared with that in the control group, and the decrease was most significant in the AS + OP groups $(\mathrm{P}<0.01)($ Table IV).

\section{Discussion}

AS is a chronic autoimmune inflammation characterized by familial aggregation. Axial skeletal lesion is common in AS patients and incidence is higher in males than in females; It has been proved that occurrence of AS is closely correlated 
with HLA-B27, but the pathogenesis of this disease still has not been fully elucidated. Animal model is an important tool to the study human autoimmune diseases, but HLA-B27 transgenic animal model has the shortcomings of long manufacturing cycle, mild symptoms, difficult operation, high cost and different clinical manifestations to AS (10). Proteoglycans can induce the progressive polyarthritis, and its progression is very similar to the clinical manifestations of AS (11). BALB/c mice are proteoglycan-susceptible mice. In the proteoglycan-induced $\mathrm{BALB} / \mathrm{c}$ mouse model, inflammation starts in sacroiliac joint and tendon inflammation, and then gradually affects multiple intervertebral discs, which is similar to the progression of AS. Besides, incidence rate of arthritis in F2-generation mice is $43.5 \%$, and that of spondylitis is $60 \%$. With the advantages of simple operation, short cycle and obvious symptoms, proteoglycan-induced AS mouse model has become an important tool to study AS (6).

OP refers to a systemic bone metabolic disease in which low bone mass (namely the decreased bone mineral density) and abnormality in qualitative structure of bone tissues lead to increased bone fragility and decreased bone strength, easily causing fractures (12). OP affects approximately 9 million new cases per year worldwide, and incidence of this disease shows an increasing trend, causing serious medical and financial burden to society and family (13). Pain, mostly low back pain, is the most common symptom of OP. Patients with severe AS may suffer from fracture or even death (14). OP animal model is divided into four types (15): hormone intervention type $(16,17)$, disuse type (18), nutritional type (19) and other types (20). Tail-suspension method induces disuse type OP model. Tail-suspension-induced AS is characterized by minimal injury and simple operation.

AS patients are prone to be affected by OP. BALB/c mice were used as subjects in our study to investigate and compare the changes in bone mineral density and bone metabolism in AS mice complicated with OP. AS mouse model, OP mouse model and AS complicated with OP mouse model were established, and the changes in bone mineral density, bone biomechanics and bone metabolic indexes were compared to those of control group. It was found that the bone mineral density and bone strength in OP model were significantly decreased compared with those in the control group, indicating that the OP model was established successfully, and obvious bone destruction existed in mouse OP model. Bone mineral density and bone strength were also decreased in AS model, and the decrease in AS + OP model was most significant, indicating that bone destruction is the most serious in AS mice complicated with OP. Significant differences in serum Ca, ALP and TRACP $(21,22)$ were found in each treatment group compared with the control group. Serum Ca and TRACP were significantly increased, while ALP was decreased obviously, and the changes were most significant in AS + OP group. In this study, changes in bone mineral density and bone metabolic indexes were consistent with clinical manifestations of patients. Clinical studies showed that the incidence rates of OP and bone mass loss in AS patients were higher compared with other groups of patients, and most patients with AS combined with OP suffer from decreased bone mineral density and abnormal bone metabolism $(4,23)$.
The model of AS complicated with OP was successfully established by using BALB/c mice as the research object. The model was easy to established with short period and low cost. The changes of bone mineral density and bone metabolism were studied and compared. It is consistent with clinical manifestations, which provides a basis for further research on mechanism and drugs. There were some shortcomings in this study due to the limited resources. Only a single animal model was used in this experiment, and the results can be more reliable if the study is repeated using multiple animal models. Moreover, only the changes in bone mineral density and bone biomechanics were detected, and our future studies will try to provide more detailed information on bone changes using micro-computed tomography (CT) scanning.

\section{Acknowledgements}

Not applicable.

\section{Funding}

No funding was received.

\section{Availability of data and materials}

The datasets used and/or analyzed during the present study are available from the corresponding author on reasonable request.

\section{Authors' contributions}

$\mathrm{ZBH}, \mathrm{BW}$ and SKW were devoted to collecting and interpreting the data. ZBH drafted the manuscript. ZMZ revised it critically for important intellectual content. JCS, MX and ZMZ were responsible for the conception and design of the study. All authors read and approved the final manuscript.

\section{Ethics approval and consent to participate}

The study was approved by the Animal Ethics Committee of Affiliated Hospital of Guangdong Medical University (Zhanjiang, China).

\section{Consent for publication}

Not applicable.

\section{Competing interests}

The authors declare that they have no competing interests.

\section{References}

1. Sampaio-Barros PD, Keiserman M, Meirelles ES, Pinheiro MM, Ximenes AC, Azevedo VF, Bonfiglioli R, Carneiro S, Ranza R, Bernardo WM, et al; Spondyloarthritis Commision of the Brazilian Society of Rheumatology: Recommendations for the management and treatment of ankylosing spondylitis. Rev Bras Reumatol 53: 242-257, 2013.

2. Colbert RA, Tran TM and Layh-Schmitt G: HLA-B27 misfolding and ankylosing spondylitis. Mol Immunol 57: 44-51, 2014. 
3. Westerveld LA, Verlaan JJ and Oner FC: Spinal fractures in patients with ankylosing spinal disorders: A systematic review of the literature on treatment, neurological status and complications. Eur Spine J 18: 145-156, 2009.

4. Klingberg E, Nurkkala M, Carlsten $\mathrm{H}$ and Forsblad-d'Elia $\mathrm{H}$ : Biomarkers of bone metabolism in ankylosing spondylitis in relation to osteoproliferation and osteoporosis. J Rheumatol 41: $1349-1356,2014$.

5. Klingberg E, Geijer M, Göthlin J, Mellström D, Lorentzon M, Hilme E, Hedberg M, Carlsten $\mathrm{H}$ and Forsblad-D'Elia $\mathrm{H}$ : Vertebral fractures in ankylosing spondylitis are associated with lower bone mineral density in both central and peripheral skeleton. J Rheumatol 39: 1987-1995, 2012.

6. Bárdos T, Szabó Z, Czipri M, Vermes C, Tunyogi-Csapó M, Urban RM, Mikecz K and Glant TT: A longitudinal study on an autoimmune murine model of ankylosing spondylitis. Ann Rheum Dis 64: 981-987, 2005.

7. Glant TT, Finnegan A and Mikecz K: Proteoglycan-induced arthritis: Immune regulation, cellular mechanisms, and genetics. Crit Rev Immunol 23: 199-250, 2003.

8. Glant TT and Mikecz K: Proteoglycan aggrecan-induced arthritis: A murine autoimmune model of rheumatoid arthritis Methods Mol Med 102: 313-338, 2004.

9. Jing D, Cai J, Wu Y, Shen G, Zhai M, Tong S, Xu Q, Xie K, Wu X, Tang C, et al: Moderate-intensity rotating magnetic fields do not affect bone quality and bone remodeling in hindlimb suspended rats. PLoS One 9: e102956, 2014.

10. Tan X, Xu YY, Qiu DN, Huang RY and He YT: Research progress of classification and pathogenesis in ankylosing spondylitis animal models. Chin J Tissue Eng Res 21: 1783-1789, 2017.

11. Zhang Y, Guerassimov A, Leroux JY, Cartman A, Webber C, Lalic R, de Miguel E, Rosenberg LC and Poole AR: Arthritis induced by proteoglycan aggrecan G1 domain in BALB/c mice. Evidence for $\mathrm{t}$ cell involvement and the immunosuppressive influence of keratan sulfate on recognition of $t$ and $b$ cell epitopes. J Clin Invest 101: 1678-1686, 1998.

12. Papapoulos SE: Anabolic bone therapies in 2014: New boneforming treatments for osteoporosis. Nat Rev Endocrinol 11: 69-70, 2015.

13. Hernlund E, Svedbom A, Ivergård M, Compston J, Cooper C, Stenmark J, McCloskey EV, Jönsson B and Kanis JA: Osteoporosis in the European Union: Medical management, epidemiology and economic burden. A report prepared in collaboration with the International Osteoporosis Foundation (IOF) and the European Federation of Pharmaceutical Industry Associations (EFPIA) Arch Osteoporos 8: 136, 2013.
14. Nazrun AS, Tzar MN, Mokhtar SA and Mohamed IN: A systematic review of the outcomes of osteoporotic fracture patients after hospital discharge: Morbidity, subsequent fractures, and mortality. Ther Clin Risk Manag 10: 937-948, 2014.

15. Shahnazari M, Wronski T, Chu V, Williams A, Leeper A, Stolina M, Ke HZ and Halloran B: Early response of bone marrow osteoprogenitors to skeletal unloading and sclerostin antibody. Calcif Tissue Int 91: 50-58, 2012.

16. He X, Wang J, Li M, Hao D, Yang Y, Zhang C, He R and Tao R: Eucommia ulmoides Oliv.: Ethnopharmacology, phytochemistry and pharmacology of an important traditional Chinese medicine. J Ethnopharmacol 151: 78-92, 2014.

17. Falcai MJ, Louzada MJ, de Paula FJ, Okubo R and Volpon JB: A modified technique of rat tail suspension for longer periods of observation. Aviat Space Environ Med 83: 1176-1180, 2012.

18. Agata U, Park JH, Hattori S, Iimura Y, Ezawa I, Akimoto T and Omi N: The effect of different amounts of calcium intake on bone metabolism and arterial calcification in ovariectomized rats. J Nutr Sci Vitaminol (Tokyo) 59: 29-36, 2013

19. Oršolić N, Goluža E, Dikić D, Lisičić D, Sašilo K, Rođak E, Jeleč Z, Lazarus MV and Orct T: Role of flavonoids on oxidative stress and mineral contents in the retinoic acid-induced bone loss model of rat. Eur J Nutr 53: 1217-1227, 2014.

20. Guo YB, Ma RF, Wang LL, Tang YQ, Li H, Zhang DW and Niu JZ: The research progress in animal osteoporotic models and the evaluating methods. Chin J Osteoporos 9: 1149-1154, 2015.

21. Halleen JM, Tiitinen SL, Ylipahkala H, Fagerlund KM and Väänänen HK: Tartrate-resistant acid phosphatase $5 b$ (TRACP 5b) as a marker of bone resorption. Clin Lab 52: 499-509, 2006

22. Hlaing TT and Compston JE: Biochemical markers of bone turnover - uses and limitations. Ann Clin Biochem 51: 189-202, 2014.

23. Davey-Ranasinghe N and Deodhar A: Osteoporosis and vertebral fractures in ankylosing spondylitis. Curr Opin Rheumatol 25: 509-516, 2013.

This work is licensed under a Creative Commons Attribution-NonCommercial-NoDerivatives 4.0 International (CC BY-NC-ND 4.0) License. 